University of Berlin. He pioneered the use of group theory to explore the symmetry properties of atoms. For this he was awarded the Nobel Prize in Physics in 1963, the only one won by the martians. Strangely, Hargittai has the least to say on him - perhaps he was the least colourful.

Teller was one of Werner Heisenberg's students at the University of Leipzig and went on to make important contributions to molecular physics, astrophysics and nuclear physics. His period at Los Alamos was central to his political development. There he read Arthur Koestler's Darkness at Noon, which reminded him of the appalling treatment of his Russian friend and colleague Lev Landau at the hands of the NKVD, the Soviet Union's secret police, and he became a virulent anti-communist. Teller became a leading figure in the Manhattan Project and was obsessed with developing a nuclear weapon that would relegate the bombs dropped on Japan to mere firecrackers. The result was a serious falling out with others in Los Alamos, notably Robert Oppenheimer, who had no interest in Teller's project to make a thermonuclear bomb and afterwards disagreed with its development.

Apart from Szilárd, the martians were fanatical about the cold war. Hargittai discusses this in detail while criticizing Teller's "reckless" testimony against Oppenheimer in 1953.

This is an important story that needs to be told, and Hargittai tells it well, although I would liked to have learnt more about the martians' creativity. Their politics aside, they were brilliant thinkers who were able to spot connections among apparently unconnected disciplines and thus identify fundamental problems - and then solve them.

Arthur I. Miller is emeritus professor of history and philosophy of science at University College London. His latest book, Empire of the Stars: Friendship, Obsession and Betrayal in the Quest for Black holes, was shortlisted for the Aventis Prize.

\title{
Women or just good scientists?
}

\section{Out of the Shadows: Contributions of Twentieth-Century Women to Physics edited by Nina Byers \& Gary Williams Cambridge University Press: 2006. 498 pp. $€ 30, \$ 35$}

\section{Patricia Fara}

"I do not agree with sex being brought into science at all. The idea of 'woman and science' is completely irrelevant. Either a woman is a good scientist, or she is not." Not the provocative statement of a modern feminist, but a plea for equality voiced a century ago by Hertha Ayrton, the electrical experimenter who, in 1904 , became the first woman allowed to present her own paper at the Royal Society in

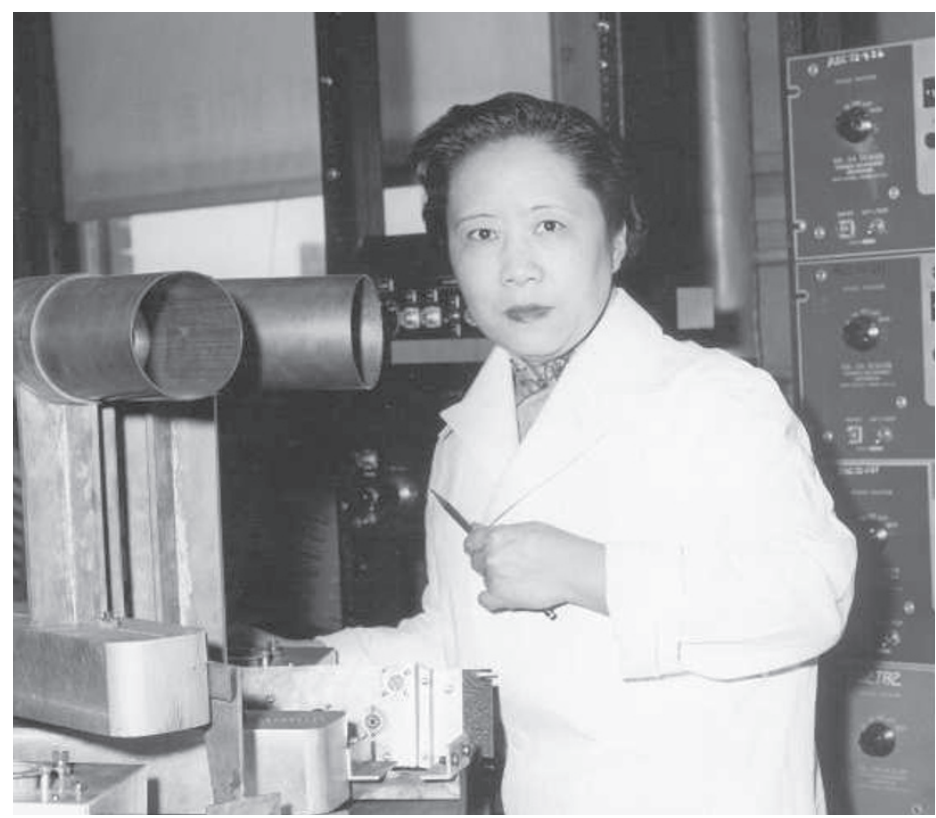

Noether and Dorothy Hodgkin (hardly a physicist), make yet another appearance, even though the sole factor that unites them - the gender that made it so hard for them to succeed - is deliberately scarcely mentioned.

The contributors were asked to submit short accounts divided into two sections: 'important contributions' and 'biography'. Many of the brisk summaries of scientific discoveries seem oddly redundant - anyone who can follow the boxed discussions of Ricci tensors, $4 \mathrm{~S}$ or string theory does not need to read them. The editors' prescriptive format has resulted in a book packed with facts, occasionally relieved by a brief anecdote - ideal for diligent students preparing accurate but unreflective assignments.

Nevertheless, the index provides clues to more interesting stories about this book's subjects. The long list of 'firsts' reveals that it was not until 1962 that the French Academy of Science admitted a woman, Marguerite Perey, and that the first woman to receive an honorary doctorate from Princeton University was the physicist Chien-Shiung Wu in 1958. The entries under 'Nobel prize' are dominated by women said to have been unjustly passed over, including astrophysicist Jocelyn Bell Burnell, nuclear physicist Lise Meitner and chemist Agnes Pockels (strangely, Rosalind Franklin is absent, despite the presence of another X-ray crystallographer, Kathleen Lonsdale, one of the first two women elected to the Royal Society in 1945). The heading 'Nazis' - referring to the plight of Myriam Sarachik, Marietta Blau, Hertha Sponer and others - demonstrates that, contradicting the editors' desires, biographical accounts often demand discussions of discrimination.

As Byers' introduction points out, most of the contributors are practising scientists who are unused to writing history. Although they each provide a short bibliography, they have mostly omitted the many excellent books and articles written by professional historians of science. This collection would have been of more value for aspiring young women if it had provided a more nuanced appreciation of how individual scientists have been converted into exaggerated stereotypes. Curie, for instance, is often depicted as the laboratory equivalent of a domestic drudge, a selfless heroine who neglected her health and her appearance while she systematically processed tonnes of dirty pitchblende to isolate radium. Such presentations reinforce the view that female scientists are a substandard breed, neither normal women nor stellar intellects. In his foreword, Freeman Dyson perceptively criticizes the editors for not including younger physicists, who would have provided more relevant role models. He also pinpoints what remains, unfortunately, excellent advice for any ambitious woman: marry the right man.

Patricia Fara is at Clare College, University of Cambridge, Cambridge CB2 1TL, UK. Her recent books include Pandora's Breeches: Women, Science and Power in the Enlightenment (2004). 